\title{
A utopia do Reino diante das distopias
}

Pe José Abel de Sousa ${ }^{1}$

Como ponto de partida para a dinâmica inicial sobre a compreensão do cristianismo relacionado ao diálogo inter-religioso, cabem alguns esclarecimentos iniciais quanto aos termos. Em relação ao sentido-base, é necessário a consideração de elementos fundamentais de um termo presente nos mais diversos contextos e abordado com conotações igualmente diversas. No aspecto contextual, merece destaque a significação em determinada situação de discurso, em certas circunstâncias. Quanto à natureza do diálogo, deve-se ter presente a situação cultural, bem como a consideração das dificuldades em realizar o diálogo devido ao individualismo e à hegemonia neoliberal. Entretanto, há, por outro lado, muitas pessoas com atitudes de abertura e desejo de diálogo, cujos fundamentos estão na exigência da própria verdade estrutural e conjunturalmente.

\section{Introdução}

Em relação à situação da temática do diálogo inter-religioso cabem perguntas a serem elencadas, pois elas podem alterar a abordagem, mas o principal intuito é a busca de uma maior clareza possível quanto à escolha feita. Levando em consideração a vontade de Jesus "de que todos sejam um" (Jo 17,21-23), o que tem impedido, da parte da fé cristã e/ou católica, que este desejo se torne realidade? O ponto de partida é o pressuposto da fé cristã como identidade a ser afirmada, porém, em chave de prática ecumênica.

Dada a expressa vontade de Jesus Cristo que o Evangelho chegue até os confins do mundo (Mt 24,14; At 1,8), cabe atualmente a pergunta sobre como anunciar o Evangelho no contexto de diversidade religiosa e de crescente pluralidade cultural. Tal fato impele os cristãos a uma revisão da forma de empreender a evangelização, problemática que se situa no âmbito da inculturação da fé.

Considerando a existência das grandes tradições religiosas, reflete-se sobre qual é o caminho de salvação que cada uma propõe. Toda religião, em princípio, deve ser tida como verdadeira, enquanto constitui um caminho salvífico. Conhecer as grandes tradições religiosas nelas mesmas, como caminho de salvação, pode ser feito de modo mais feliz se for sem comparações, sem preconceitos, podendo haver questionamentos mútuos contanto que esses sejam sempre respeitosos.

Diante da existência das grandes tradições religiosas e do caráter (absoluto) do cristianismo, como compreender a viabilidade do diálogo entre elas? O que o cristianismo pode oferecer e reciprocamente receber nesse diálogo? Ao longo desse processo dialogal, alguns

\footnotetext{
1 Doutor em Teologia Pastoral pela Puc-Rio, professor de Cristianismo e Bíblica da Cultura Religiosa da Puc-Rio e Coordenador da Pastoral Universitária da Puc-Rio.
} 
elementos importantes da compreensão do cristianismo podem ser modificados na compreensão, mas não na essência.

A existência das grandes tradições religiosas suscita questões de como interpretar a fé cristã e católica diante do fato da multiplicidade das grandes religiões como sendo um dado da realidade - sinal dos tempos - que faz com que a fé cristã se veja obrigada a reinterpretar-se. Diante disso se põe a pergunta sobre como entender o desígnio salvífico de Deus em relação às pessoas e qual é o valor salvífico de cada uma das tradições religiosas?

\section{Caminhos diversos, fundamentados na perspectiva teológica cristã em vista de superação de obstáculos epistemológicos}

Há algumas afirmações tradicionais que dificultam o ingresso na temática do diálogo inter-religioso. Uma dessas é a concepção de um Deus que elege um povo e deixa os outros em um estado de religião natural. Segundo essa concepção, inexiste a ideia da vontade universal salvífica de Deus, bem como igualmente o seu respectivo significado ontológico.

Há abordagens diversas quanto ao diálogo inter-religioso. Depende de como se compreende as religiões da humanidade. A história comparada e a fenomenologia ou filosofia das religiões procedem a uma observação, avaliação, reflexão ou comparação dos fenômenos religiosos a partir do método pretensamente objetivo da ciência positiva ou especulativo da filosofia, renunciando, naturalmente, a qualquer juízo absoluto de valor quanto à unicidade ou superioridade de uma tradição religiosa. Cada religião é estudada como única, diferente, original a seu modo, sem pretensão de sobrepor uma à outra, de modo absoluto.

No sentido mais estrito da palavra, essa perspectiva não viabiliza o diálogo interreligioso, mas, quiçá, possibilita um primeiro passo de conhecimento da outra religião. $\mathrm{O}$ diálogo exige mais. O ponto de partida aqui é o da teologia cristã e da unicidade da fé cristã e a partir daí estabelecer a reflexão e o diálogo com outras religiões.

A perspectiva desta questão situa-se no contexto do diálogo inter-religioso, no sentido de ir ao encontro das religiões a partir da fé cristã. Busca-se encontrar a relação mútua entre Jesus Cristo e as mais diversas tradições religiosas da humanidade. Neste espírito se pensa a missão do cristão. Prefere-se falar em "tradições religiosas da humanidade" em vez de "religiões não cristãs" (Souza Gomes, 1986: 33-49).

Como tal realidade foi compreendida ao longo da história? No âmbito práticoespeculativo, que realidade de facto e de jure do pluralismo religioso interroga a fé cristã e recebe dela significado em vista de um diálogo inter-religioso? Este é um caminho possível, a partir do qual aprofunda-se a fé cristã diante do pluralismo cultural e da diversidade religiosa e, então, se abrem perspectivas para o diálogo inter-religioso.

Denominar as outras religiões com o termo "religiões não cristãs" implica ter presente que essa expressão pode evocar uma conotação ofensiva, uma vez que define as outras religiões pelo que não são e não pelo que são, ou se propõem a ser. Nega-se a sua identidade 
e a sua especificidade enquanto expressões religiosas. Estabelece-se o cristianismo a priori, como norma absoluta, olvidando-se que ele representa uma das tradições religiosas da humanidade. Identifica-se, sem mais, o cristianismo com a fé vivida em Jesus Cristo, que, esse sim, e não o cristianismo, constitui-se o verdadeiro ponto de partida da reflexão.

\section{A antiguidade e a atualidade da problemática do pluralismo cultural e da diversidade religiosa}

As religiões encontram-se com um "homem planetário" em um mundo que se interliga cada vez mais. Esse ser humano reivindica não tanto a pertença a uma religião, mas o reconhecimento de sua humanidade que grita contra as ameaças de morte. E. Balducci vê nos místicos, prescindindo das religiões de que são membros,

as primeiras testemunhas da unidade do gênero humano; diante deles, um filósofo como Hegel é apenas um pensador genial da tribo prussiana...Os místicos já inventaram uma Koiné, uma linguagem ecumênica na qual a espécie humana se reflete em sua unidade profunda, apesar das distâncias de tempo e de espaço e das diversas tradições. (Balducci, 1990)

Os dados estatísticos levantam algumas sérias interrogações. $\mathrm{Na}$ Índia, de mais de 900 milhões de habitantes, $2,5 \%$ são cristãos. Na China, reduz-se ainda mais a proporção. Nesse contexto, como interpretar a seguinte citação bíblica: "portanto, vão e façam discípulos de todas as nações, batizando-os em nome do Pai e do Filho e do Espírito Santo" (Mt 28,19)?

Já há séculos vem acontecendo certa orientalização do Ocidente. Fenômeno que se tem acentuado nos dias atuais, com a sedução causada nos ocidentais pelas místicas hinduístas e budistas. Constroem-se, no Ocidente cristão, "ashrams hindus e mosteiros budistas" (Campbell, 1997).

Evidentemente essa nova percepção da presença plural das religiões não nasce unicamente de uma constatação geográfica, já muito antiga, mas da entrada da consciência histórica dentro da Igreja católica. Percebe-se melhor, na Igreja católica, a relevância dos fatores históricos e culturais, tais como o respeito às suas concepções religiosas. Isso favorece o verdadeiro diálogo inter-religioso. Ao tomar consciência da historicidade de seus fundamentos, do limite de suas expressões religiosas, dos próprios preconceitos com que julga as outras religiões e, portanto, da riqueza de tais religiões, a lgreja católica pode então estabelecer um autêntico diálogo (Thompson, 1976: 382-388).

H. Kung apresenta razões que põem a questão na primeira linha. Trata-se de uma questão de paz e de verdade.

Não haverá paz entre as nações, se não existir paz entre as religiões. Não haverá paz entre as religiões, se não existir diálogo entre as religiões. Não haverá diálogo entre as religiões, se não existirem padrões éticos globais. Nosso planeta não irá sobreviver, se não houver um ethos global, uma ética para o mundo inteiro. (Kung, 2004: 17) 
A história mostra como muitas das lutas mais sangrentas e cruéis da humanidade foram inspiradas e legitimadas pelas religiões.

\section{A verdade relacionada às questões religiosas}

As religiões evocam com agudeza o problema da verdade. Por mais que se estudem as convergências e divergências entre elas, permanece, todavia, a pergunta se há uma ou várias religiões verdadeiras. Se frequentemente a questão da verdade esteve vinculada à da belicosidade, o desinteresse pela verdade pode conduzir à desorientação do pensar e do agir (Kung, 1999: 315-17). De fato, o cristianismo sempre considerou a questão da religião ou da fé como uma questão da verdade, já que se trata de algo tão importante e fundamental como a salvação. Nesse sentido, se considerava uma traição à verdade qualquer posição relativista.

Essa postura tem se tornado cada vez mais insustentável, quer por motivos teológicos, quer filosóficos, quer por outras ciências positivas ou motivos práticos. Teológicos, em relação a ter-se maior consciência do mistério salvífico, universal e insondável de Deus e que cada religião, de certo modo, expressa. Filosóficos, no que se refere à linguagem religiosa, sendo de natureza autoimplicativa e existencial, que revela antes a verdade do sujeito que a do objeto. Científicos no sentido de que os estudos antropológicos e sociológicos possibilitam, de um lado, constatar a profunda relação entre as religiões e as tradições culturais em que os seres humanos nascem e vivem e, de outro, a impossibilidade de valorizar mais uma cultura que outra. Destarte, parece ser mais consentâneo afirmar que toda cultura, e, por conseguinte, todas as religiões são verdadeiras, autênticas, únicas e incomparáveis entre si, desde que cumpram sua função de mediação da transcendência e da salvação. E, finalmente, por motivos práticos, no sentido em que $B$. Spinoza dizia que a verdade de uma religião tende a resolver-se no seu caráter moral de inspirar e comandar a conduta prática enquanto o aspecto doutrinal cumpre a função de apoio e referência simbólicos (Gesché, 1990: 105-118).

É comum a tentação de se transferir a questão teórica da verdade para uma solução pragmática. A religião seria verdadeira à medida que ela mostrasse serviços de bem à humanidade no espírito da frase evangélica de que se conhece a árvore pelos frutos (Mt 7,1520). Por esse caminho se dá uma espécie de disputa entre ortodoxia e ortopráxis.

$\mathrm{Na}$ teologia, a solução de outrora para a relação do cristianismo com outras religiões à base do destino salvífico do indivíduo por meio da incorporação à Igreja pelo batismo de desejo (expressão utilizada pelo Papa Pio XII em Mystici corporis Christi) revela o insuficiente pressuposto a-histórico segundo o qual o indivíduo se salva apesar de seu contexto pagão e não nele ou por causa dele. Tal resposta teológica inviabilizava o diálogo com as outras religiões. No início dos anos 1960, no século passado, o Concílio Vaticano II deu um significativo passo ao aceitar o caráter salvífico universal da graça na história humana e nas tradições religiosas. A percepção positiva a respeito das outras tradições religiosas, vistas 
como um lugar de experiência religiosa e salvífica para seus membros, é o que possibilita o diálogo. Isso significa que se reconhece em todas as religiões a possibilidade de absoluto. A consciência de historicidade não se opõe a essa percepção de absoluto das religiões (Thompson, 1976: 391).

Avançando um pouco mais, se chega a perguntas tais como: por que se torna necessário ser igreja ou cristão, se a graça salvadora de Deus atinge todos? Considerando a universalidade do desígnio salvífico de Deus, se pode perguntar pela contribuição do diálogo e enriquecimento mútuo dos cristãos em relação às religiões e às culturas? (Schineller, 1976: 545-566).

\section{Elementos intrínsecos do cristianismo quanto ao diálogo entre a identidade e diferença}

De acordo com A. Gesché, é possível partir do próprio cristianismo para se questionar se ele possui em si elementos que permitam responder a esta pergunta do pluralismo religioso e não ir em busca de debates sobre conceitos como universalidade, unidade, superioridade ou especificidade (Gesché, 1990: 105).

O momento atual parece paradoxal em relação à possibilidade do diálogo religioso. De um lado avança uma avassaladora onda de massificação, de nivelamento geral de tudo e de todos. A ciência, a tecnologia, a razão instrumental instalam o mundo da homogeneidade. Os computadores reconhecem em qualquer parte do mundo os mesmos sinais, leem os mesmos impulsos. Em princípio, isso possibilita um macro diálogo, já que se pode cruzar a mesma linguagem tecnológica. Entretanto, outro movimento, também muito impressionante, penetra até os rincões mais profundos das pessoas, a saber, a consciência e defesa da própria individualidade diante das incursões externas.

Mário F. Miranda denomina de "pluralismo inédito" o fato antigo da multiplicidade de religiões atingir realmente o Brasil (Miranda, 1996: 12), questionando a hegemonia até então absoluta da Igreja católica. O pluralismo atualmente faz parte da agenda católica, ele tornou-se destino inevitável da fé e da teologia católicas. Ao contrário da visão ingenuamente otimista do século $\mathrm{XIX}$ e início do século $\mathrm{XX}$, que correspondia à epopeia missionária, o cristianismo não conquistou o conjunto do planeta e as grandes religiões do mundo dão provas de crescente vitalidade.

\section{Diversidade de conceitos quanto à concepção de religião}

O conceito de religião não é unívoco. As próprias religiões trabalham concepções diferentes de religião e o estudioso das ciências da religião pode ter dificuldades para elaborar esse conceito. $E$, além do mais, dependendo do ângulo sob o qual a religião é estudada, os conceitos recebem diferentes nuances. A fim de se entender o que venha a ser religião, o recurso à etimologia pode oferecer uma primeira pista. O termo apresenta duas possíveis 
origens. Religio - religião - provêm de religare, cujo significado é: "religação do ser humano com Deus" (Lactâncio: Div Inst VII 28). Cícero tem também essa concepção de religião, quando fala de impedir ou liberar tal religião. No entanto, ele aponta outra versão interpretativa. Antes de tudo, distingue religião de superstição, como fizeram os antepassados e filósofos. Superstição é rezar e sacrificar continuamente para garantir que os filhos sobrevivam a eles. Em seguida, liga a etimologia de religião ao verbo religare, conotando a ideia de escolher e cuidar, preparar para o culto, para a "veneração dos deuses" (Cícero, 195: 71).

A religião diz respeito à percepção de uma dupla esfera da realidade, de um lado, humana, profana e, de outro, divina, sagrada. A religião tem a pretensão de articulá-las por meio de símbolos, ritos, mitos, relatos maravilhosos, crenças, imagens, testemunhas de revelação, esperanças, comportamentos, disciplina. A religião pode ser considerada também como experiência pessoal e/ou como instituição. Enquanto experiência, remete ao fato de o ser humano possuir uma dimensão religiosa. A palavra "religiosidade", que serve de tradução à famosa expressão homo religiosus, exprime melhor este conceito que o termo religião.

A experiência do sagrado pode ser descrita com duas palavras: fascinante e atemorizante. É um sentimento difícil de ser definido. Assemelha-se ao sentido estético. Provém das emoções, experiências espirituais, afetivas. O ser humano, de acordo com a maioria das antropologias, tem uma atitude, um sentimento de abertura, uma sensibilidade especial face ao sagrado. As pessoas são bem diferentes quanto à sua sensibilidade religiosa, além dessa experiência variar também conforme a idade ou situação existencial. O sagrado pode apresentar-se diante delas sob diversas formas. A fenomenologia religiosa estuda precisamente essa experiência.

Enquanto instituição, o termo "religião" é definido como um sistema solidário de crenças e de práticas relativas às questões sagradas. É um empreendimento do ser humano em vistas de construir um cosmos sagrado (Berger, 2004), de ligar-se com o sagrado segundo essa concepção o mundo se divide entre sagrado e profano. A função da religião é introduzir a pessoa em um sistema lógico que vai além da existência humana.

$\mathrm{Na}$ Antiguidade cristã, teve lugar uma compreensão imperial da religião. A garantia da ordem pública era mantida pelo imperador que, sendo cristão, teve a pretensão de instaurar na terra a legislação desejada por Deus. O matrimônio entre religião e Estado se estendia à ideia mística como expressão do eros da alma individual para Deus. Nesse caso, a religião seria, antes de tudo, sinônimo de "religiosidade", correspondendo ao que se convencionou chamar de homo religiosus. A ideia monástica reduzia a religião à disciplina própria dos batizados que fizeram voto de perfeição (Despland, 1993: 1685). Essa concepção monástica predominou na Idade Média. Juntava-se à ideia de ordem religiosa a aprovação por parte do magistério. Posteriormente, amplia-se tal concepção às pessoas de bem (peregrino, cruzado). Isso se manifestava nos bons costumes adquiridos pelos povos cristãos. A religião tornou-se um fato de civilização. A Reforma, sobretudo a de recorte calvinista e anglicano, via o ideal de 
realização pública da religião cristã em um país e nos corações pela pregação bíblica, instaurando uma ordem civil cristã livremente consentida (Herrero, 1985: 20-29).

A partir do século XVI e XVII, o termo religião começou a ser empregado no coletivo, sendo aplicado ao islamismo, às tradições indianas e orientais, cada vez mais conhecidas na Europa, com o risco de generalizações e considerações abstratas, esquemáticas, descuidando da dimensão de fé das pessoas. As religiões, portanto, são vistas como sistema de crença, ritos, práticas que conformam as nações, regulam com exclusividade a relação do ser humano com Deus. Daí nascerem avatares da religião como o exclusivismo e seu oposto, que é o relativismo, e a reificação, fonte de autoritarismo opressor, como sendo algo que emerge do mundo da irracionalidade. Quanto mais se caminha rumo à civilização, mais se crê poder prescindir da religião.

A Modernidade assistiu a um processo de transformação do papel da religião na sociedade. Padeceu intensa secularização indo do deísmo ao ateísmo. Deixou a esfera pública e transladou-se para o âmbito privado. Hoje vive-se o paroxismo de tal situação. Resumidamente pode-se dizer que a sociedade moderna defende a total imanência diante da natureza, das relações humanas, da história e do futuro. Consequentemente, afirma-se a inutilidade da religião, do transcendente. L. Feuerbach, S. Freud e F. Nietzsche se destacaram por afirmar que a religião seria alienação subjetiva, doença infantil ou uma atitude de fracos. D. Bonhoeffer reconhece o desaparecimento do a priori religioso (Tunes, 2008: 160). Desta sorte, se passa da secularização como ideologia (militância laicizante na formação das sociedades modernas) para a secularização enquanto mentalidade (difusão e fixação do espirit laique na expressão simbólica dos valores considerados próprios da sociedade moderna) e como "forma de vida" (que se exprime máxime na laicização da razão nas linguagens codificadas da cultura moderna). O sagrado deixa de ser "fonte" para tornar-se "objeto" da cultura.

Na pós-modernidade há uma explosão de surtos religiosos. Há um retorno do sagrado, um reencantamento do mundo, um fascínio do religioso, uma onda mística, esoterismo e muitas outras expressões reveladoras de um panorama inesperado e bem diferente da onda de secularização verificada na década de 1960 do século passado.

Há oscilação entre considerar a religião como um sistema de ritos ou como expressão do ser humano na sua dimensão religiosa concreta. Na verdade, a religião tem esta dupla dimensão de realidade objetiva, tradição acumulada, aspecto visível com doutrinas, ritos, constituições, artes etc., de um lado, e, de outro, de realidade subjetiva, de fé pessoal, de aspecto interno, não observável nem passível de ser conhecida.

A dificuldade de se elaborar um conceito único de religião provém da grande diversidade das religiões. Desde o monoteísmo, como é o caso do judaísmo e islamismo, passando por um monoteísmo trinitário, como é o caso do cristianismo, e por um politeísmo até uma religião sem um Deus específico, como é o caso do budismo. 
Religião é a realização socioindividual de uma relação do ser humano com uma realidade verdadeira e suprema, seja ela compreendida da maneira como for (Deus, o Absoluto, Nirvana, Shûnyatâ, Tao etc). Tradição e comunidade são dimensões básicas para todas as grandes religiões: doutrina, costumes e ritos são suas funções básicas; transcendência no espaço ou no tempo, como salvação, iluminação ou libertação, tudo isso são preocupações que caracterizam as religiões (Kung, 1986: 6).

\section{Conclusão}

A experiência outrora utópica do diálogo inter-religioso levanta a questão do conceito de religião. Esse diálogo não se faz a partir da comparação entre religiões, mas entre pessoas que praticam e vivem a religião no nível da experiência pessoal ou mesmo no interior da própria fé. A pluralidade das religiões surge precisamente por causa das liberdades de Deus e da criatura nessa relação religiosa.

Mais do que respostas prontas e acabadas, preferimos apresentar algumas perguntas fundamentais que envolvem a problemática vista a respeito da relação entre o cristianismo e o diálogo inter-religioso. Qual é a mensagem fundamental do cristianismo que pode contribuir para as culturas e religiões? Em que reside sua força emancipatória? Como formular a universalidade salvífica de Jesus em um mundo cultural e religioso cioso das singularidades, autonomias das culturas e tradições religiosas sem parecer que se tenha a pretensão etnocêntrica, dominadora, impostora, massacrante de culturas e religiões? Como ainda se pode falar do específico da experiência cristã com sua pretensão de sentido universal em um mundo de falibilismo, relativismo, ceticismo diante de verdades, valores, bens? Percebe-se que reina a desconfiança quanto a um sentido global religioso a respeito dos sentidos parciais das diversas experiências religiosas. A pergunta referente à inculturação da fé cristã alija do horizonte da teologia o eixo da libertação? Está aí o desafio de iluminar o chão do existir humano (a cultura) a partir do caminho de Jesus. O ser humano não se entende unicamente a partir das estruturas, mas como alguém que vive nessas mesmas estruturas de um determinado modo (cultura). Outro desafio é anunciar o evangelho desde as culturas como questão e solução radical, já que alcança o ser humano nesse lugar fundamental para além das culturas.

A verdade das religiões é absoluta. Nelas se joga o destino definitivo dos seus membros. Não valem unicamente em função e em relação à revelação bíblica. As religiões têm valor em si mesmas. Por isso é que não cabe fazer comparações entre religiões como se fossem realidades relativas. Cada religião é capaz de expressar uma relação absoluta. Sob esse aspecto, elas não são complementares. São as pessoas que se podem enriquecer mutuamente. A conversão não é resultado do estudo comparado das religiões para escolher a melhor, mas a resposta à manifestação e o chamado de Deus por meio e dentro de uma tradição determinada. Na religião nada é puramente humano. Toda religião é verdadeira 
enquanto tematiza a relação constitutiva, salvífica do ser humano com Deus. Elas variam no modo e na intensidade da verdade. Captam a irradiação amorosa do Mistério nos seus limites. Toda realização histórica é sempre limitada, por isso vale para toda religião a famosa afirmação de Santo Agostinho: si comprehendis, non est Deus.

\section{Referências bibliográficas:}

BALDUCCI, E. L'uomo planetário. S. Domenico di Fiesole: Cultura della Pace, 1990.

BERGER, P. O dossel sagrado. Elementos para uma teoria sociológica da religião. São Paulo: Paulus, 2004.

CAMPBELL, C. A orientalização do Ocidente: reflexões sobre uma nova teodiceia para um novo milênio. Religião e Sociedade, 18(1), p. 5-29, 1997.

CÍCERO. De natura Deorum acadêmica. Londres: William Heinemann, 1951.

DESPLAND, M. Religion. In: POUPARD, P. (dir). Dictionnaire des religions. Paris: PUF, 1993. v.II: $1684-1689$.

GESCHÉ, A. El cristianismo de las demás religiones. Selecciones de teología 29(114), p. 103118, 1990.

HERRERO, F. X. Filosofia da religião e a crise da fé. Dialética do Sagrado Cristão. Síntese (Nova Fase) 13 (35), p. 18-39, 1985.

KUNG, H. Religiões do mundo: em busca dos pontos comuns. Campinas: Verus, 2004.

KUNG, H. Teologia a caminho: fundamentação para o diálogo. São Paulo: Paulinas, 1999.

KUNG, H. Introdução: o debate sobre o conceito de religião. Concilium, 1(203), p. 5-10, 1986.

MIRANDA, M. F. Um catolicismo desafiado. Igreja e pluralismo religioso no Brasil. São Paulo: Paulinas, 1996.

SCHINELLER, J. P. Christ und Church. A Spectrum of Views. Theological Studies, 37, p. 545566, 1976.

SOUZA GOMEZ, A. Secularização em declínio e potencialidade transformadora do sagrado. Síntese Nova Fase), 14 (37), p. 33-49, 1986.

THOMPSON, W. The risen Christ, transcultural consciousness, and the encounter of the world religions. Theological Studies 37, p. 381-409, 1976.

TUNES, S. M. O cristianismo não religioso em Bonhoeffer e Vattimo. Horizonte - Revista de Estudos de Teologia e Ciências da Religião, 6(12), p. 157-168, 3 jun 2008. 